\title{
Photofrin-mediated Photodynamic Therapy of Rat Palatal Mucosa: Normal Tissue Effects and Light Dosimetry
}

\author{
J.M. NAUTA ${ }^{a}$, H.L.L.M. VAN LEENGOED ${ }^{b}$, M.J.H. WITJES ${ }^{a}$, J.L.N. ROODENBURG ${ }^{a}$, \\ P.G.J. NIKKELS ${ }^{c}$, S.L. THOMSEN ${ }^{d}$, J.P.A. MARIJNISSEN ${ }^{b}$, W.M. STAR ${ }^{b}$ \\ a Department of Oral and Maxillofacial Surgery, University Hospital Groningen, The Netherlands \\ ${ }^{b}$ Department of Clinical Physics, Dr Daniel den Hoed Cancer Centre, Rotterdam, The Netherlands \\ ${ }^{c}$ Department of Pathology, University Hospital Groningen, The Netherlands \\ ${ }^{\circ}$ Laser Biology Research Laboratory, Departments of General Surgery and Pathology, M.D. Anderson Cancer Center, \\ Houston, Texas, USA \\ Correspondence to J. M. Nauta, Department of Oral and Maxillofacial Surgery, University Hospital Groningen, \\ P.O. Box 30.001, 9700 RB Groningen, The Netherlands \\ Paper received 26 May 1996
}

\begin{abstract}
Photodynamic therapy (PDT) is a treatment modality with potential application for premalignant lesions and squamous cell carcinoma of the oral mucosa. PDT in principle has dual selectivity. This may result from a 'preferential' retention of the photosensitizer in target tissue. In addition, the photodynamic activity will be limited to the irradiated area because PDT will not affect tissues in the absence of excitation light. The specificity of PDT is limited by the fact that normal tissues also retain the photosensitizer to some degree, which makes these tissues susceptible to PDT damage. To optimize PDT for oral malignancies, a study was undertaken on normal tissue to investigate the responses in rat palatal mucosa and surrounding anatomical structures. Eighty male Wistar rats were used in the study. Photofrin was administered i.v. at four doses $\left(0,2.5,5\right.$ or $10 \mathrm{mg} \mathrm{kg}^{-1}$ body weight). Irradiation for PDT was performed $24 \mathrm{~h}$ later. An argon pumped dye laser system was used to produce light of two different treatment wavelengths (514.5 and $625 \mathrm{~nm}$ ), and various energy density levels $\left(0,25,50,100\right.$ or $\left.200 \mathrm{~J} \mathrm{~cm}^{-2}\right)$. Early effects of PDT were studied at 2 days and late effects at 2 months after treatment. Twenty-four hours after i.v. administration of Photofrin, it was found that PDT affects normal tissues of the oral cavity both macroscopically and microscopically. Combinations of photosensitizer doses $\geq 5 \mathrm{mg} \mathrm{kg}^{-1}$ and light doses $\geq 100 \mathrm{~J} \mathrm{~cm}^{-2}$ caused severe and permanent damage to the palatal mucosa and adjacent normal structures such as palatal bone and dentition.

Light scattering and internal reflection usually raise the fluence rate in tissue above the irradiance of the incident beam. In an additional study using six male Wistar rats, the energy fluence rate at two treatment wavelengths $(514.5$ and $625 \mathrm{~nm})$ was measured ex vivo in the palatal mucosa and adjacent anatomical structures. As expected, the energy fluence rates were wavelength, tissue and depth dependent. At the air-mucosa boundary, light of $625 \mathrm{~nm}$ was found to have a three-times higher fluence rate than the primary incident beam. Under similar conditions, the fluence rate of $514.5 \mathrm{~nm}$ was found to be less, but still twice as high as the primary incident beam. At deeper levels of the rat maxilla, fluence rates were still elevated compared with the incident beam. For $625 \mathrm{~nm}$ light, this phenomenon was observed up to the level of the nasal cavity. These increased fluence rates could largely explain the pattern of damage to normal mucosa and surrounding anatomical structures.
\end{abstract}

\section{INTRODUCTION}

Photodynamic therapy (PDT) is a treatment modality with potential application for premalignant lesions and squamous cell carcinoma of the oral mucosa. PDT is based on the dyesensitized photo-oxidation of biological matter in the target tissue (1). The photosensitizers Haematoporphyrin derivative $(\mathrm{HpD})$, or more commonly Photofrin (the semi-purified version 
of $\mathrm{HpD}$, enriched in the 'active fraction'), are frequently used for PDT. Currently, a number of photosensitizers are being clinically tested, but to date Photofrin is the only photosensitizer that has been approved for a limited number of indications in the USA, Canada, Japan and the Netherlands. The advantage of PDT over conventional surgical or radiotherapeutic treatment may be its potential dual selectivity. Selectivity may be obtained by a 'preferential' retention of the photosensitizer in target tissue. In addition, the photodynamic activity will be limited to the irradiated area because PDT will not affect tissues in the absence of excitation light. However, the selectivity of Photofrin is far from ideal because normal tissue also retains the photosensitizer to some extent, and is, therefore, susceptible to PDT damage (2-6). Knowledge of the morphological alterations induced by PDT in the area of the tumour and in the region of the adjacent normal tissues is therefore important with respect to the early and late complications of PDT (7). Furthermore, it is important to determine the optimal combination of photosensitizer and light dose that will result in minimal or at least reversible damage to the surrounding normal tissues. Proper knowledge of light dosimetry is, therefore, needed in order to compare, reproduce and predict the effects of PDT, and to establish the factors that determine success or failure. However, so far little attention has been paid to light dosimetry in clinical PDT (8-11). Frequently, the distribution of the photosensitizer in tissue remains unknown, and consequently, the actual light dose absorbed by the photosensitizer is unknown. In PDT of superficial tumours, the incident power per unit area (W $\mathrm{m}^{-2}$ ) multiplied by the irradition time is used to describe the light dose. In tissue, the energy fluence rate can vary, however, due to the phenomena of light scattering and internal reflection at tissue boundaries. In oral tissue there are potentially many boundaries which could influence the homogenous distribution of light, eg the air-mucosa and mucosa-bone boundaries. Better knowledge of the distribution of light in the treated tissues can be obtained by calculations using a mathematical description of light propagation in tissue, using estimates of the scattering properties and optical absorption of the treated tissue, and by in vivo measurement of the fluence rate of light (12-15). This may help to understand the treatment results.
Red light in the range of $625-630 \mathrm{~nm}$ is most commonly used in clinical PDT with porphyrin-based photosensitizers such as Photofrin. Although porphyrins have a low absorption at these wavelengths, this excitation wavelength is often chosen because of its increased optical penetration compared with light of shorter wavelengths. For PDT of small, superficially growing tumours, the use of $514.5 \mathrm{~nm}$ green light might be preferred. The porphyrin molecule can be excited at a wavelength where it has a higher absorption, and damage to anatomical structures beyond the target volume can be minimized (16-18).

The aim of this study was two-fold. First, to describe the effect of PDT on normal rat palatal mucosa and surrounding normal tissues; various combinations of photosensitizer and light doses at two different treatment wavelengths were compared. Second, to describe light fluence as a function of wavelength and site in the normal rat palate and adjacent anatomical structures using the two most common excitation wavelengths for Photofrin excitation, and to compare this with the treatment results.

\section{MATERIALS AND METHODS}

\section{Animals}

Eighty healthy, 6-8-week-old male Wistar rats (CDL-Groningen, The Netherlands) were used in this study. The rats were randomly divided into two groups of 40 rats. One group was treated with light of $625 \mathrm{~nm}$, based on the study of Star et al (12), and the other group was treated with light of $514.5 \mathrm{~nm}$. Each group of 40 rats was again randomly divided into 10 groups of four rats. Each group of four rats was treated with a different combination of photosensitizer dose and light dose (Table 1). During administration of the photosensitizer and during photodynamic therapy, the animals were anaesthetized with a combination of $\mathrm{N}_{2} \mathrm{O} / \mathrm{O}_{2} /$ Halothane. Approval for this study was obtained from the University Animal Experiments Committee (FCC-0472).

\section{Excitation light}

A tuneable argon pumped dye laser system (Spectra-Physics, 171 and 375B) was used to produce $514.5 \mathrm{~nm}$ (green) light or $625 \mathrm{~nm}$ (red) 
Table 1. Summary of the treatment plan of the effect of PDT on normal rat palatal mucosa and surrounding anatomical structures

\begin{tabular}{rccc}
\hline $\begin{array}{l}\text { Protocol } \\
\text { number }\end{array}$ & $\begin{array}{c}\text { Number } \\
\text { of rats }\end{array}$ & $\begin{array}{c}\text { Photofrin dose } \\
\left(\mathrm{mg} \mathrm{kg}^{-1} \mathrm{bw}\right)\end{array}$ & $\begin{array}{c}\text { Incident } \\
\text { light dose } \\
\left(\mathrm{J} \mathrm{cm}^{-2}\right)\end{array}$ \\
\hline & & 0 & 200 \\
I & 8 & 2.5 & 200 \\
II & 8 & 2.5 & 100 \\
III & 8 & 5 & 100 \\
IV & 8 & 2.5 & 50 \\
V & 8 & 5 & 50 \\
VI & 8 & 10 & 50 \\
VII & 8 & 5 & 25 \\
VIII & 8 & 10 & 25 \\
IX & 8 & 10 & 0 \\
X & 8 & & \\
\hline
\end{tabular}

The irradiance of both treatment wavelengths (514.5 and $625 \mathrm{~nm}$ ) was $60 \mathrm{~mW} \mathrm{~cm}-2$ and the photosensitizer-light interval was $24 \mathrm{~h}$. Half of the animals of each treatment protocol were killed after 2 days to examine the short-term effects. The remaining rats were kept alive up to 2 months after treatment to examine the long-term effects.

light. The fluence rate of the incident beam for both wavelengths was $60 \mathrm{~mW} \mathrm{~cm} \mathrm{~cm}^{-2}$, and the light dose was 0-200 $\mathrm{J} \mathrm{cm}^{-2}$ (Table 1). A light delivery system was developed which enabled the delivery of light to an area of about $10 \mathrm{~mm}$ in diameter, corresponding with the intermolar area of the rat palate (19).

\section{Photodynamic therapy}

Each rat was photosensitized with either 0, 2.5, 5 or $10 \mathrm{mg} \mathrm{kg}^{-1}$ bw Photofrin (Quadra Logic Technologies, Vancouver, BC, Canada), by intravenous injection in the tail vein. The animals were housed under reduced light conditions to avoid unwanted photodynamic action. Twenty-four hours after administration of the photosensitizer, the palates were irradiated. From every treatment group, two rats were killed $48 \mathrm{~h}$ after. PDT and two after 2 months, to examine both short- and longterm effects. The rats were killed by an intracardial injection of sodium pentobarbital (Euthesate).

\section{Histological preparation}

The palate, including the surrounding hard and soft tissues, was removed in one piece and photographed. The specimens were fixed in $4 \%$ formalin, and subsequently decalcified for approximately 4 weeks in $25 \%$ formic acid with $0.34 \mathrm{M}$ trisodium citrate dihydrate. The degree of decalcification was checked by X-ray analysis. The palates were dehydrated and embedded in paraffin. Histology slides of $7 \mu \mathrm{m}$ were cut transversely through the region of the second molar. The slides were stained with Haematoxylin and Eosin (HE) for examination by light microscopy.

\section{Macroscopic scoring system}

Changes in the macroscopic appearance of the dissected palates 2 days after PDT treatment were given a numerical score: $0=$ no clinical effect, $1=$ slight erythema, $2=$ marked erythema, $3=$ ulceration or necrosis of the epithelium (focal), $4=$ ulceration or necrosis of the epithelium (entire area), $5=$ denuded bone.

Subsequently, the macroscopic appearance of the palate 2 months after PDT was given a score: $0=$ no clinical effect, $1=$ epithelium intact, scar tissue (locally), 2=epithelium intact, scar tissue (entire area), $3=$ ulceration or necrosis of the epithelium, $4=$ denuded bone (locally), $5=$ denuded bone (entire area).

\section{Microscopic scoring system}

The histological changes were described using two grading systems. One described the shortterm histological effects (2 days after PDT), the other the long-term histological effects (2 months after PDT). In both grading systems, effects seen in the mucosa, the palatal bone and in structures beyond the palatal bone were evaluated separately. Each item of both systems was given a numerical score which varied from 0 to $2(0=$ no effect, $1=$ slight effect, $2=$ marked effect). The overall PDT-induced damage score is summarized by adding up these individual scores. For the short-term effects ( 2 days after PDT), the maximum possible score of this grading system was 54 ; for the long-term effects (2 months after PDT), this was 40 .

Microscopic changes 2 days after PDT were examined for the following items:

Mucosa: oedema, haemorrhage, parakeratosis, partial or total necrosis of the epithelial layer, vascular oedema, congestion or haemostasis of vessels, vascular thrombosis, vascular 
necrosis, disruption of lamina elastica interna of arteries.

Bone: intra-suture tissue haemorrhage, intrasuture tissue necrosis, osteocyte necrosis, bone marrow haemorrhage, haematopoietic cell loss of bone marrow.

Beyond mucosa: oedema, haemorrhage, vascular oedema, congestion or haemostasis of vessels, vascular thrombosis, vascular necrosis, disruption of lamina elastica interna of arteries, dental pulpa necrosis, increased degranulation of Goblet cells, cell necrosis of sinal epithelium, necrosis of the lacrimal gland.

Microscopic changes 2 months after PDT were examined for the following items:

Mucosa: irregular distribution of rete ridges, epithelial isles or cysts, scar tissue, foreign body reaction in mucosa, hypertrophy of vessel wall, vascular recanalization, vascular proliferation, neuronal proliferation, loss of palatal artery and vein, loss of palatal nerve.

Bone: palatal bone remodelling, loss of palatal bone.

Beyond mucosa: scar tissue, hypertrophy of vessel wall, vascular recanalization, vascular proliferation, neuronal proliferation, dental hard tissue resorption, ankylosis of root, irregular dentin formation, hyperplasia of sinus epithelium.

\section{Dosimetry experiment}

Due to the small dimensions of the rat oral cavity, it was impossible to perform dosimetry measurements in vivo. Therefore, these measurements were performed ex vivo (ie immediately after dissection of the palate and surrounding structures). Six male Wistar rats were used in this dosimetry experiment. An isotropic probe (ie a fibre-optic light detector with omnidirectional uniform response) of $0.8 \mathrm{~mm}$ diameter was calibrated in a parallel beam of light (514.5 and $625 \mathrm{~nm}$ wavelength) with an irradiance of $100 \mathrm{~mW} \mathrm{~cm} \mathrm{~cm}^{-2}$. This beam of $10 \mathrm{~mm}$ diameter was then directed to the palate simulating the light beam of the light delivery system, as used in the PDT experiments. Due to differences in isotropic probe response in tissue after calibration in air due to differences in refractive index, the readings of the probe were corrected by a factor of 1.65

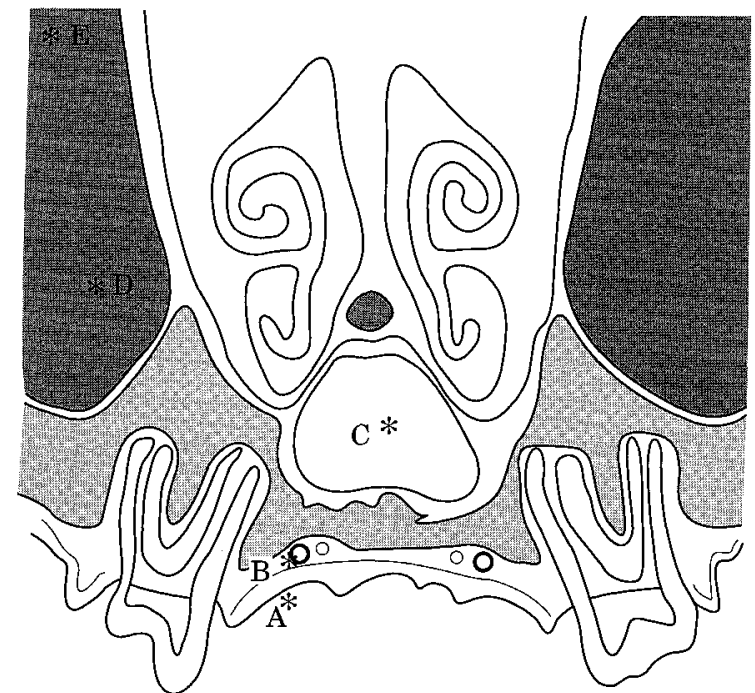

Fig. 1. Schematic drawing of the mucosa, hard palate and surrounding structures of the rat maxilla at the level of the second molar in a sagittal plane. The sites where the fluence measurements were taken are indicated. These include: $(A)$ on the air-mucosa boundary, $(B)$ at the mucosa-bone boundary, (C) in the nasal cavity, (D) in the lacrimal gland in close proximity to the molar teeth, $(E)$ in the lacrimal gland, close to the brain.

when the probe was completely surrounded by tissue, and by a factor of 1.15 when partly surrounded by tissue and partly by air $(20,21)$. Figure 1 shows a schematic drawing in a sagittal plane through mucosa, hard palate and surrounding structures of the rat maxilla at the level of the second molar. The various sites of the palatal mucosa and surrounding structures where the light fluence measurements were taken are indicated. These include: (A) the air-mucosa boundary, (B) the mucosabone boundary, (C) the nasal cavity, (D) the lacrimal gland in close proximity to the molar teeth, and (E) the lacrimal gland close to the brain.

In order to estimate the influence of internal reflection by bone, and to simulate the clinical situation when palate is lost due to tumour invasion, the epithelium of the intermolar area was dissected. Measurements were taken on top of and underneath this dissected mucosa specimen (on a black non-scattering background), directly on the denuded palatal bone, and in the nasal cavity. Comparing the results of the measurements in which the mucosa was still attached to the palatal bone, with those where the palatal mucosa was dissected and placed on a black background, yields an estimate of the portion of the light that is reflected by the palatal bone back into the 


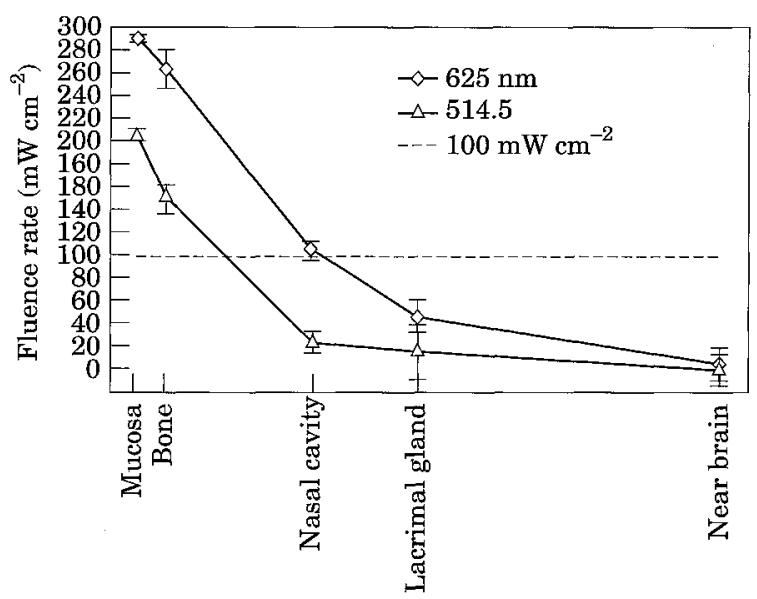

Fig. 2. Diagram showing the results of the isotropic probe measurements of the energy fluence rates of 514.5 and $625 \mathrm{~nm}$ excitation light at various sites of the oral cavity and surrounding structures, with the palatal mucosa in situ. The fluence rate of the primary incident beam (calibrated in air) was $100 \mathrm{~mW} \mathrm{~cm}^{-2}$. The beam diameter was $10 \mathrm{~mm}$.

mucosa and the light that is scattered by the mucosa only.

\section{RESULTS}

During follow-up, the rats were weighed twice a week. After an initial slight loss of weight during the first week after treatment, all rats showed an increase in weight, but no correlation was found between weight and treatment parameters.

\section{Dosimetry}

Figure 2 shows a line diagram of the fluence rates of the rat palatal mucosa and surrounding structures for both excitation wavelengths. The measurements plotted in this graph were taken with the mucosal layer in situ. The fluence rates at $625 \mathrm{~nm}$ were always higher than those of $514.5 \mathrm{~nm}$, and found to be significantly different in a paired Student's $t$-test $(p<0.05)$. At the surface of the mucosa, the fluence rate at $625 \mathrm{~nm}$ was almost three times higher than that of the primary incident light beam. At the mucosa-bone boundary, the fluence rate was more than 2.5 times higher. The fluence rate of light at $514.5 \mathrm{~nm}$ was two times higher at the surface of the mucosa, and at the mucosa-bone boundary exceeded the irradiance of the incident beam.
In Table 2, the actual fluence rates and additional measurements taken after dissection of the palatal mucosa are listed. Overall results indicate that both mucosa and palatal bone contributed considerably to light scattering and internal reflection. The measurements taken after dissection of the palatal mucosa showed that the average fluence rate of $514.5 \mathrm{~nm}$ light at the mucosa-air boundary was about 0.8 times the value measured while the palatal mucosa was still attached to the palatal bone. Under similar conditions, the average fluence rate of $625 \mathrm{~nm}$ light was about 0.7 times the value measured while the palatal mucosa was still attached to the palatal bone. Measurements underneath the dissected palatal mucosa also revealed a decrease of the actual fluence rate of 0.8 and 0.7 times for $514.5 \mathrm{~nm}$ and $625 \mathrm{~nm}$, respectively.

\section{Macroscopic changes}

Figure 3(a,b) depicts the mean overall macroscopic damage score 2 days after treatment of the normal palate with various combinations of photosensitizer and light doses for both treatment wavelengths. As expected, the effect on the normal palate and surrounding structures of the oral cavity was found to be-both sensitizer- and light-dose dependent. Higher sensitizer doses and higher light doses resulted in more damage than combinations in which lower drug, or lower light doses, were used. Except for one rat in which locally denuded bone was evident, the most severe damage of the mucosa presented as ulceration or necrosis with haemorrhage and oedema of the entire treated area. When no sensitizer or no light was applied, no clinical damage of the mucosa of the intermolar area was observed. Two days after PDT, no real difference was observed in the amount of macroscopic damage between the two treatment wavelengths.

In Fig. 3(c,d) the mean overall macroscopic damage score at 2 months after treatment is shown. For most of the combinations of sensitizer-light doses, the epithelium of the intermolar area had macroscopically regenerated to an intact epithelial layer. In the majority of cases, however, scar tissue was evident. In these cases, the appearance of the normal anatomy of the intermolar area was disturbed. The rugal pattern had disappeared and the palatal mucosa gave a more whitish dense impression in which the underlying palatal 
Table 2. Isotropic probe measurements of the fluence rates of light of 514.5 and $625 \mathrm{~nm}$ at various sites of the rat oral cavity and surrounding structures

\section{$514.5 \mathrm{~nm}$ wavelength $625 \mathrm{~nm}$ wavelength}

Mean s.e.m. (\%) Mean s.e.m. (\%)

Before dissection of the palatal mucosa

Air-mucosa boundary $\left(\mathrm{A}^{*}\right)$

Mucosa-bone boundary $\left(\mathrm{B}^{*}\right)$

Nasal cavity $\left(\mathrm{C}^{*}\right)$

Lacrimal gland-near molars $\left(D^{*}\right)$

Lacrimal gland-near brain $\left(\mathrm{E}^{*}\right)$

After dissection of the palatal mucosa

At the mucosa (black background)

Under the mucosa (black background)

On denuded palatal bone

Nasal cavity

$\begin{array}{rrrr}207 & 6 & 291 & 3 \\ 153 & 13 & 265 & 8 \\ 25 & 9 & 106 & 9 \\ 17 & 24 & 48 & 14 \\ 1 & 14 & 6 & 15 \\ & & & \\ 166 & 7 & 207 & 3 \\ 129 & 6 & 189 & 6 \\ 194 & 6 & 287 & 4 \\ 55 & 14 & 158 & 7\end{array}$

The fluence rate of the primary beam (calibrated in air) was $100 \mathrm{~mW} \mathrm{~cm}^{-2}$. Measurements were taken both before and after dissection of the palatal mucosa to examine the specific influence of mucosa and bone on the fluence rates. $\mathrm{A}^{*}-\mathrm{E}^{*}$ corresponds with the sites as depicted in Fig. 1.
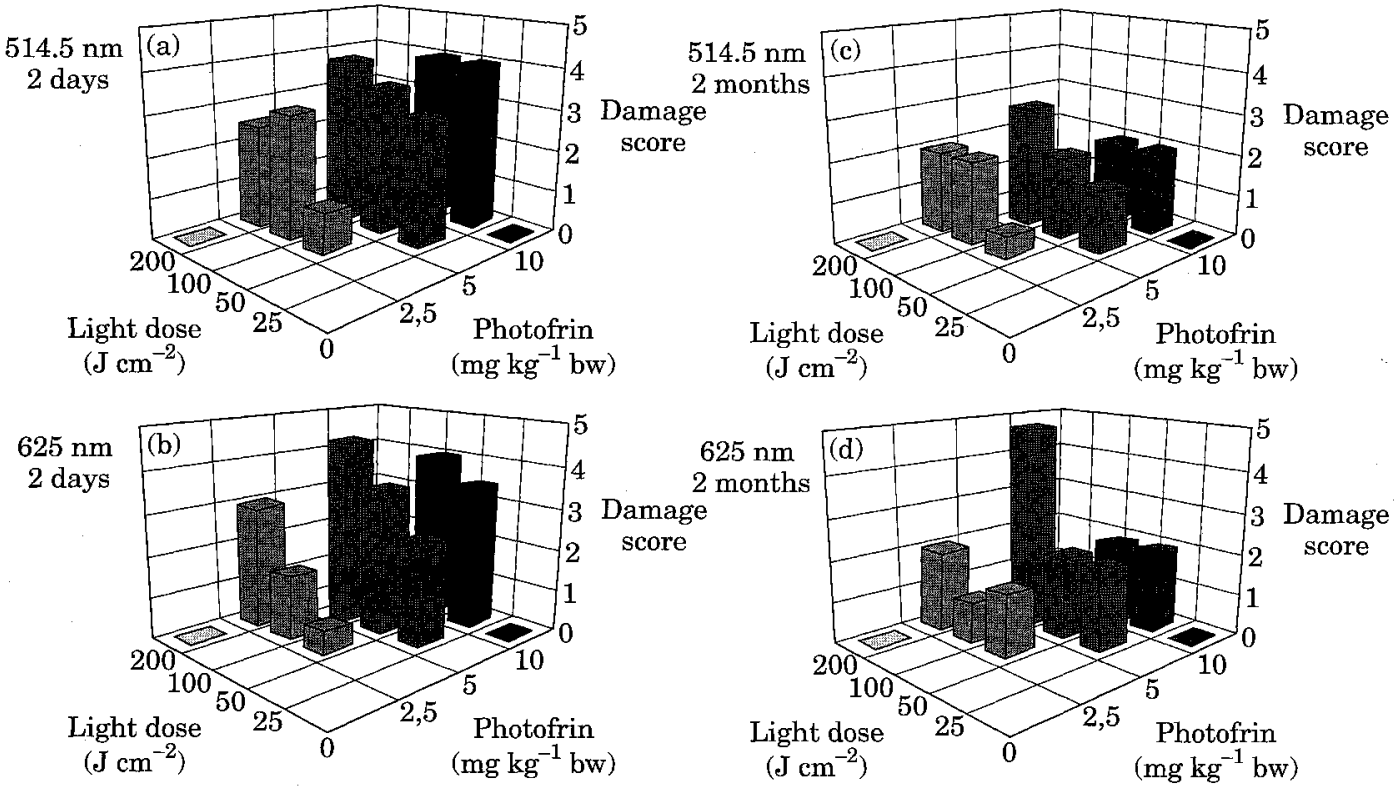

Fig. 3. The overall macroscopic damage scores 2 days and 2 months after PDT. (a) Two days after PDT, at $514.5 \mathrm{~nm}$. (b) Two days after PDT, at $625 \mathrm{~nm}$. (c) Two months after PDT, at $514.5 \mathrm{~nm}$. (d) 2 months after PDT, at $625 \mathrm{~nm}$. The $x$-axis represents the light dose in $\mathrm{Jcm}^{-2}$, the $y$-axis the damage score, and the $z$-axis the Photofrin dose in $\mathrm{mg} \mathrm{kg}^{-1} \mathrm{bw}$.

blood vessels were no longer visible. In three rats, the epithelial integrity was disturbed with the denuded palatal bone clearly visible. Two of these rats were treated with $625 \mathrm{~nm}$, the other with the $514.5 \mathrm{~nm}$, all in Protocol IV. The absence of photosensitizer or light in the initial treatment caused no observable damage, resulting in normal macroscopic appearance of the palatal mucosa. Overall, no apparent differences were found between the two treatment wavelengths in the amount of macroscopic damage at 2 months.

\section{Microscopic changes}

Figure 4(a,b) shows the mean overall microscopic damage score of the effect of PDT on the normal palate and surrounding structures of the rat oral cavity, 2 days after treatment. The overall damage effect of light of $625 \mathrm{~nm}$ 

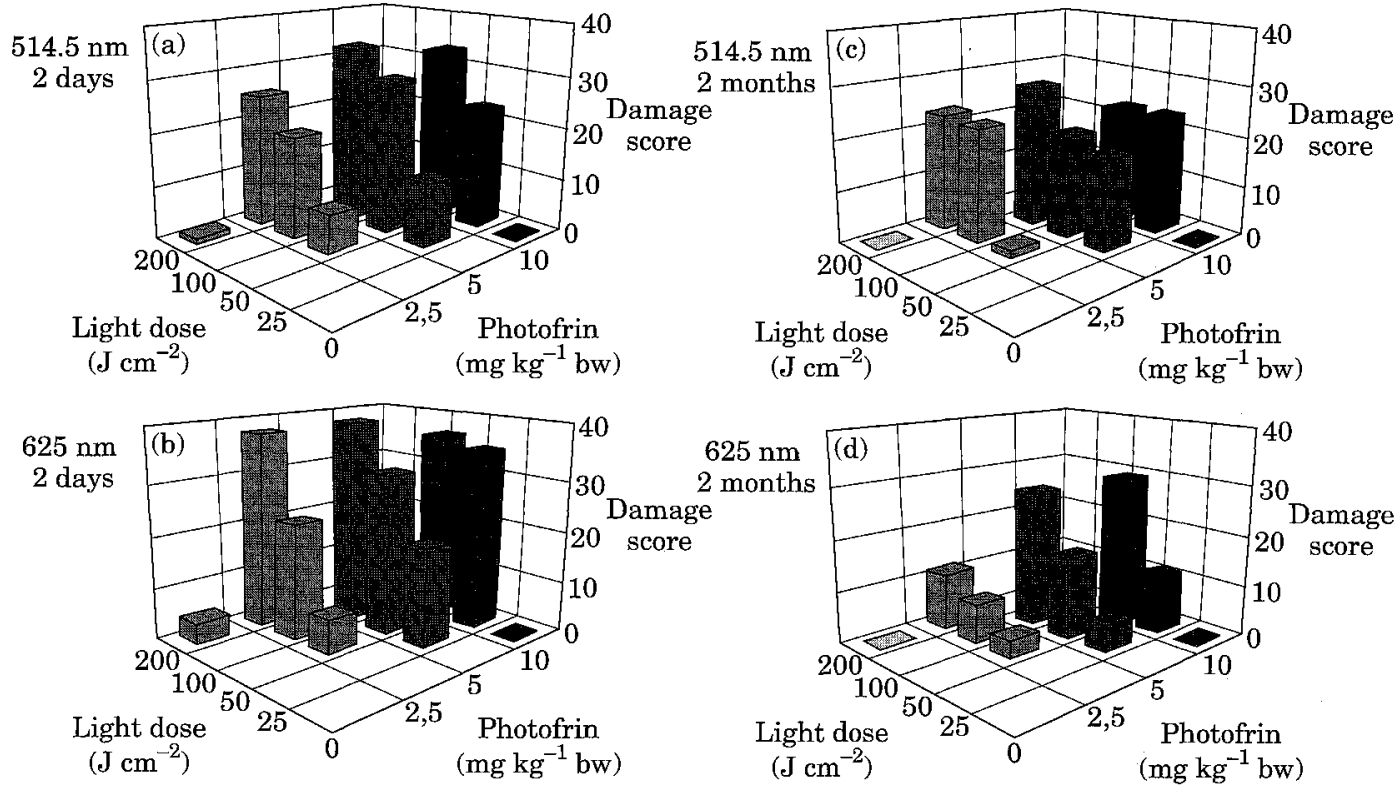

Fig. 4. The overall microscopic damage scores 2 days and 2 months after PDT. (a) Two days after PDT, at $514.5 \mathrm{~nm}$. (b) Two days after PDT, at $625 \mathrm{~nm}$. (c) Two months after PDT, at $514.5 \mathrm{~nm}$. (d) Two months after PDT, at $625 \mathrm{~nm}$. The $x$-axis represents the light dose in $\mathrm{Jcm}^{-2}$, the $y$-axis the damage score, and the $z$-axis the Photofrin dose in $\mathrm{mg} \mathrm{kg}^{-1} \mathrm{bw}$.

exceeded that of light of $514.5 \mathrm{~nm}$. For both excitation wavelengths, this overall effect increases with increasing Photofrin dose, as well as with increasing light dose. The damage score of light at $625 \mathrm{~nm}$ mainly exceeded that at $514.5 \mathrm{~nm}$ because of effects on structures beyond the palatal bone. As expected, the highest Photofrin dose (10 $\left.\mathrm{mg} \mathrm{kg}^{-1}\right)$ used in this study caused no measurable effect in the absence of light (Protocol X). On the other hand, a high dose of light $\left(200 \mathrm{~J} \mathrm{~cm}^{-2}\right)$ in the absence of the photosensitizer (Protocol I), resulted in a small but distinctive amount of damage. This effect was present for both wavelengths, and was noticed only in structures beyond the palatal bone (ie epithelium of the nasal sinus and lacrimal gland).

Figure 4(c,d) shows the mean overall microscopic damage score 2 months after PDT. At this time, in contrast to the effects seen at 2 days after PDT, the tissue damage of light of $514.5 \mathrm{~nm}$ exceeded that of $625 \mathrm{~nm}$. When damage to mucosa, palatal bone and structures beyond the palatal bone were judged separately, the long-term damage to the mucosa was found to contribute most to the overall conclusion that light at $514.5 \mathrm{~nm}$ was more damaging than that at $625 \mathrm{~nm}$. Most striking differences between the mucosa scores of both wavelengths were found in Protocols II and III. The minor damage caused by light alone, as observed at 2 days, was not present at 2 months. Increasing the drug dose or the light dose resulted in more permanent damage at 2 months.

One of the presumptions of PDT is that damage to normal tissues should be at least reversible. However, it was found that several combinations of photosensitizer and light doses resulted in permanent tissue damage (Fig. 5). This permanent damage was found to be sensitizer, light-dose and wavelength dependent. For both wavelengths, a marked loss of the palatal bone was found in Protocols IV and VI. In other combinations of sensitizer and light doses (except Protocols I and $\mathrm{X}$ ), bone remodelling or partial loss of the palatal bone was apparent. At 2 months, the effect of light of $514.5 \mathrm{~nm}$ on bone slightly exceeded that of $625 \mathrm{~nm}$. Damage to molar teeth was found for both wavelengths. Damage. was composed of resorption of dental hard tissues, ankylosis of the root (ie a bony attachment of the root with the surrounding alveolar bone, indicating regeneration after previous damage to the periodontal ligament), and the formation of irregular dentin. For both wavelengths (except in Protocols I, $\mathrm{V}$ and $\mathrm{X}$ ), damage to the dental hard tissue was evident. No apparent differences existed in the degree of damage to the dental hard tissue induced by either wavelength. Furthermore, it was found that in all cases (except in Protocols I, V and X), epithelial inclusion cysts were found within the regenerated epithelium (Fig. 6). 
(a)

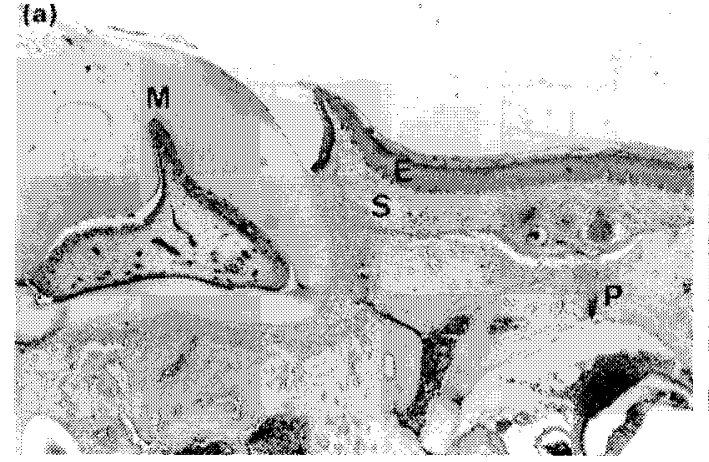

(c)

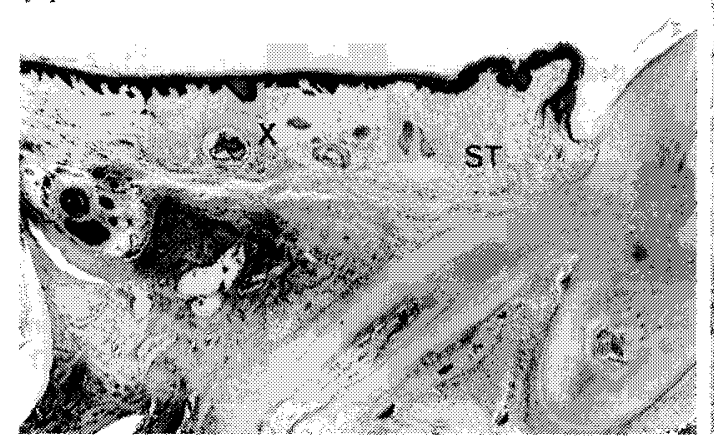

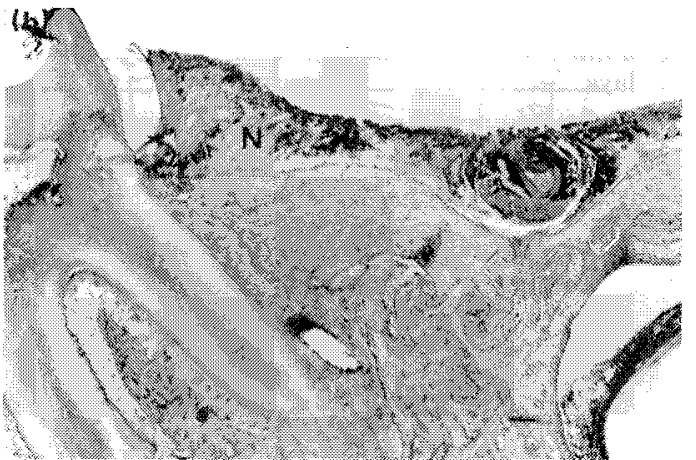

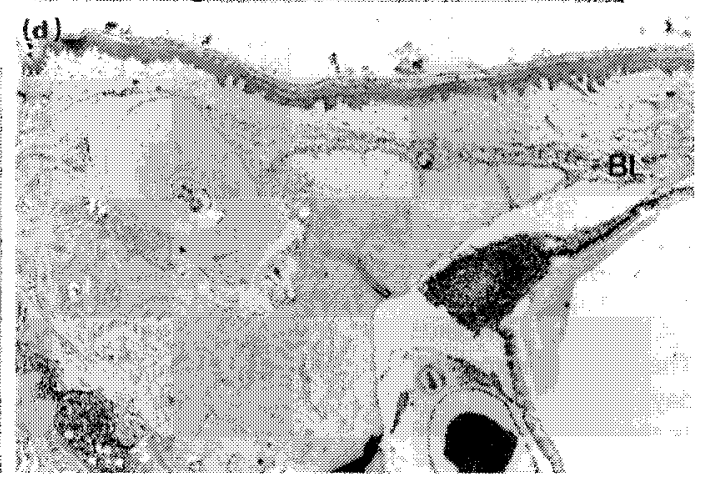

Fig. 5. Some typical examples of the histological appearance of the rat palatal mucosa after PDT. (a) Normal, untreated palatal mucosa. $E=$ epithelial layer of the palatal mucosa, $S=$ submucosa, $P=$ palatal bone, $M=\operatorname{molar}(H E, \times 40)$. (b) Two days after PDT. Treatment parameters: $625 \mathrm{~nm}, 5 \mathrm{mg} \mathrm{kg}^{-1}, 100 \mathrm{~J} \mathrm{~cm}^{-2}$. Complete loss of epithelium, bacterial overgrowth in submucosal tissue and around vessels. Severe periosteal oedema. $\mathrm{N}=$ necrotic epithelial layer $(\mathrm{HE}, \times 40)$. (c) Two months after PDT with more or less reversible damage. Treatment parameters: $514.5 \mathrm{~nm}, 5 \mathrm{mg} \mathrm{kg}{ }^{-1}, 50 \mathrm{~J} \mathrm{~cm}^{-2}$. The palate shows a normal intact epithelium with normal hyperkeratosis. The submucosa consists of a dense collagen-rich tissue (scar tissue) with epithelial islands within the submucosa. ST=scar tissue in the submucosa, $\mathrm{X}=$ epithelial islands and epithelial cyst in the submucosa $(\mathrm{HE}, \times 40)$. (d) Two months after PDT with irreversible damage. Treatment parameters: $625 \mathrm{~nm}, 5 \mathrm{mg} \mathrm{kg}^{-1}$, $100 \mathrm{~J} \mathrm{~cm}^{-2}$. Note the marked loss (BL) of palatal bone $(\mathrm{HE}, \times 40)$.

\section{DISCUSSION}

In order to treat premalignant epithelial lesions and squamous cell carcinoma of the oral mucosa with PDT, it is important to understand the effects on normal tissues. Sparing, or at least regeneration, of normal tissue is necessary in order to preserve function. Not only is it important to assess the 'treatment window' (the range of optimal combinations of sensitizer and light doses), but also to understand the light distribution in tissues to gain more knowledge of factors that lead to tissue effects. Among the large number of PDT studies, the effect of normal tissue and light distribution has received relatively little attention $(12,22-26)$.

\section{Light dosimetry}

Light scattering and internal reflection strongly influence the energy fluence rates in different tissues. The results of the present experimental study on the fluence rates in normal rat palates show that the distribution of light in oral tissue is far from homogenous. Palatal mucosa and palatal bone influence the fluence of 514.5 and $625 \mathrm{~nm}$ light. Energy fluence rates at the air-mucosa boundary were found to be twice as high for $514.5 \mathrm{~nm}$ light and three times as high for $625 \mathrm{~nm}$ light, relative to the primary incident beam with an irradiance of $100 \mathrm{~mW} \mathrm{~cm}{ }^{-2}$. The fluence rates of $625 \mathrm{~nm}$ light were always higher than those of the $514.5 \mathrm{~nm}$. This was expected because the absorption and scattering properties of tissue for green light is different from those of red light, and longer wavelengths can penetrate deeper in tissues.

The conclusions of the present study are in accordance with those of Star and Marijnissen et al $(8,13,27,28)$. At several tissue surfaces (chicken muscle, rhabdomyosarcoma, dog bladder), they found actual fluence rates that were two to six times higher than the primary incident beam. Light of $630 \mathrm{~nm}$ gave higher actual fluence rates than $514.5 \mathrm{~nm}$ light. In 

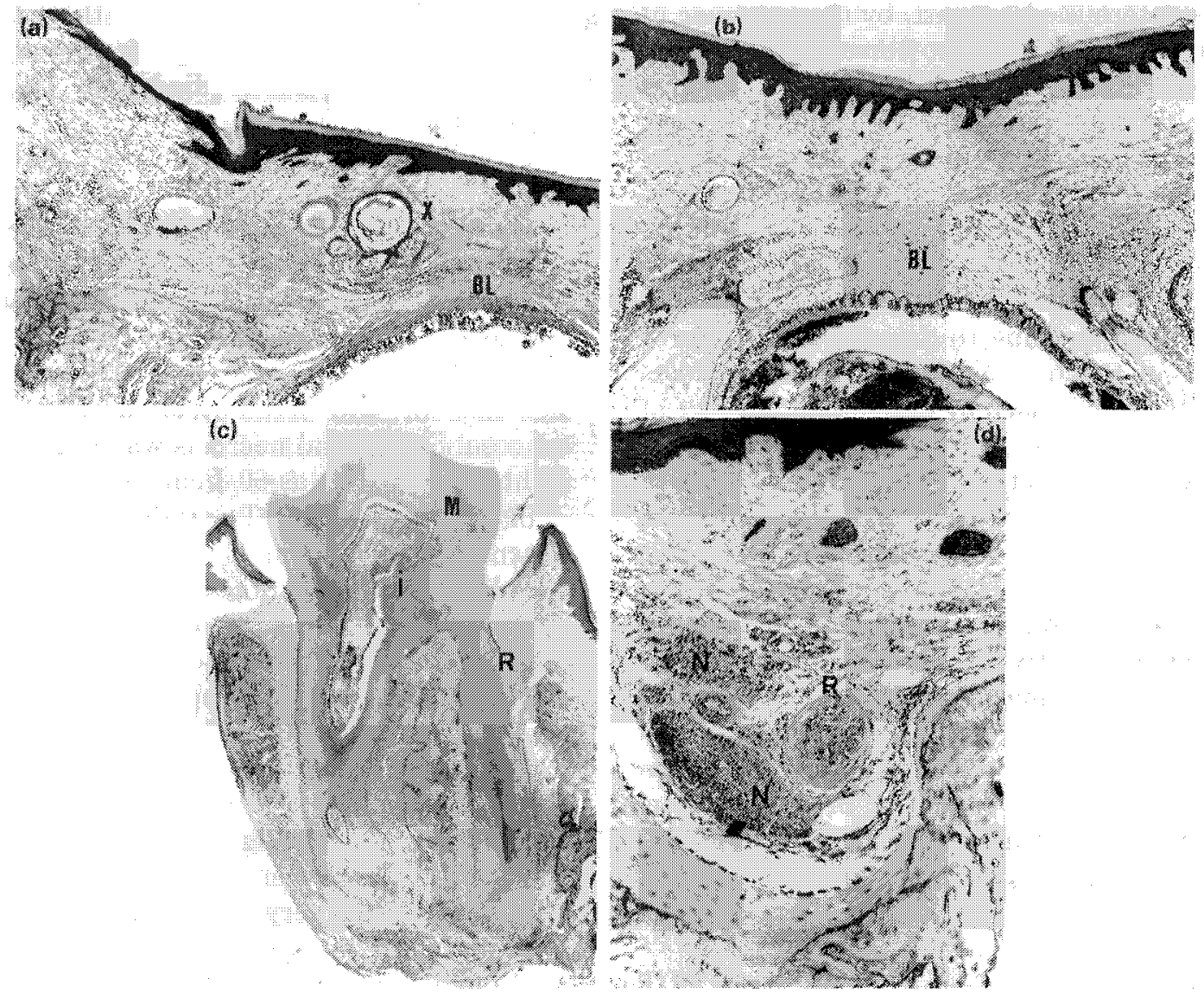

Fig. 6. Histological appearance of the long-term ( 2 months after treatment) specific damage of the rat palatal mucosa and surrounding tissues. (a) Under a normal intact epithelium with normal hyperkeratosis epithelial islands (inclusion cysts) with sebaceous differentiation, complete loss of the palatal vessel and nerve bundle can be seen. $\mathrm{X}=$ inclusion cyst, $\mathrm{BL}=$ palatal bone loss. Treatment parameters: $514.5 \mathrm{~nm}, 5 \mathrm{mg} \mathrm{kg}^{-1}, 100 \mathrm{~J} \mathrm{~cm}^{-2}(\mathrm{HE}, \times 64)$. (b) Marked loss of palatal bone. $B \mathrm{~L}=$ palatal bone loss. Treatment parameters: $625 \mathrm{~nm}, 10 \mathrm{mg} \mathrm{kg}^{-1}, 50 \mathrm{j} \mathrm{cm}-2(\mathrm{HE}, \times 64)$. (c) Damage to dental hard tissue and dental pulp. Root resportion (R) and formation of irregular dentin (I) can be seen. Treatment parameters: $625 \mathrm{~nm}, 5 \mathrm{mg} \mathrm{kg}^{-1}$, $50 \mathrm{~J} \mathrm{~cm}^{-2}(\mathrm{HE}, \times 64)$. (d) Revascularization of the palatal artery $(R)$ and proliferation of the palatal nerve $(N)$ due to previous damage. Treatment parameters: $514.5 \mathrm{~nm}, 10 \mathrm{mg} \mathrm{kg}^{-1}, 25 \mathrm{~J} \mathrm{~cm}^{-2}$ (HE, $\left.\times 160\right)$.

human whole bladder wall, PDT $(630 \mathrm{~nm})$ revealed a true light fluence (ie non-scattering incident light plus scattered light) almost five times larger than the non-scattered incident light fluence. In rat ears, Star et al (12) found the actual light fluence to be higher than the incident fluence. These actual fluence rates correlated with the relative biological effect, rather than with the incident fluence.

The results of the present dosimetry study clearly indicate that an incident light beam with an energy fluence of $100 \mathrm{~mW} \mathrm{~cm}{ }^{-2}$ at the mucosa results in a true energy fluence rate which is twice as high for light of $514.5 \mathrm{~nm}$ and three times as high for light of $625 \mathrm{~nm}$. Other structures in close proximity to the palatal mucosa, eg dentition, nasal cavity and lacrimal gland, therefore received higher doses of light. In this study, these increased fluence rates contribute considerably to PDT-induced damage of normal anatomical structures. The fluence-rate data largely explain the damage pattern seen in this study.

\section{Normal tissue effects}

Knowledge of the morphological alterations induced by PDT, not only in the area of the tumour but also in the region of the adjacent normal tissue, is important with respect to the early and late complications of PDT (7). The mechanism of accumulation of photosensitizers in tumour tissue is still largely unknown. Autoradiographic studies using $\left[{ }^{14} \mathrm{C}\right]$ and $\left[{ }^{3} \mathrm{H}\right]$-labelled porphyrins have demonstrated photosensitizer uptake in normal tissue $(2-4,29)$. As normal tissue also retains the photosensitizer to some extent, it is also susceptible to PDT. The feasibility of clinical 
PDT is determined, in part, by the response of normal tissue adjacent to tumour tissue. The ideal is to find an optimal therapeutic window, combining photosensitizer dose and light dose. Treatment under these parameters should lead to tumour destruction with only limited or at least reversible damage to the surrounding tissues. As seen in the present study, 2 days after PDT, the effect of $625 \mathrm{~nm}$ light exceeded that of $514.5 \mathrm{~nm}$, due to damage of structures beyond the mucosa. At 2 months, these effects were reversed, caused by permanent damage of the mucosal layer. Dosimetry experiments in mucosa and structures beyond the mucosa revealed that actual fluence rates of $625 \mathrm{~nm}$ light were higher than those of $514.5 \mathrm{~nm}$. Although light of $625 \mathrm{~nm}$ penetrates deeper into tissue, the increased absorption of $514.5 \mathrm{~nm}$ apparently results in more permanent damage (at a smaller tissue volume). The observation that light alone resulted in distinctive damage 2 days after PDT can be explained by the presence of endogenous porphyrins. For example, the Harderian gland, a lipid-secreting gland in the orbit in rodents, contains a large amount of endogenous porphyrin (30).

Only a few studies describe the effect of PD'T with Photofrin on normal tissues of the oral mucosa. Treatment protocols used in these studies differ from the present study, so consequently it is difficult to find analogies in PDTinduced (normal) tissue damage. Biel et al (24) studied the effect of PDT (630 nm) with Photofrin (2 $\left.\mathrm{mg} \mathrm{kg}^{-1}\right)$ and various (incident) light doses $\left(20,50,80,100\right.$ and $\left.125 \mathrm{~J} \mathrm{~cm}^{-2}\right)$ in normal tissues of the oral cavity and larynx in dogs. Similar to the results of this study, the effects appeared to be tissue and light-dose dependent. The tongue was found to be more susceptible to PDT than cheek or larynx. The degree of oedema was found to be proportional to the degree of vascularization of the organ. Light doses of up to $50 \mathrm{~J} \mathrm{~cm}^{-2}$ gave reversible damage, which resulted in complete healing of the tongue by 7 weeks. A light dose greater than $80 \mathrm{~J} \mathrm{~cm}^{-2}$ resulted in permanent ulceration with muscular fibrosis. The cheek mucosa was more resistant and tolerated treatments of up to $125 \mathrm{~J} \mathrm{~cm}^{-2}$ with minimal permanent tissue damage. These results are in accordance with the present results, where a combination of photosensitizer dose and light dose $\geq 5 \mathrm{mg}$ $\mathrm{kg}^{-1}$ and $\geq 100 \mathrm{~J} \mathrm{~cm}^{-2}$ resulted in distinct permanent damage. Due to the smaller dimension of the rat oral cavity, damage to several anatomical structures beyond the mucosal layer were observed in the present study.

Monnier et al (25) studied PDT $72 \mathrm{~h}$ after injection of Photofrin (2-3 mg kg-1 bw) in normal buccal mucosa in humans. Light doses varied from $60-240 \mathrm{~J} \mathrm{~cm}^{-2}\left(50-200 \mathrm{~mW} \mathrm{~cm}^{-2}\right)$ and thermal effects were ruled out. A control group irradiated with a light dose of $240 \mathrm{~J}$ $\mathrm{cm}^{-2}$ but received no Photofrin, showed no necrosis of the buccal mucosa. Four days after PD'T, all Photofrin-treated patients showed necrosis of the irradiated, normal buccal mucosa. Superficial necrosis was induced with light doses as low as $60 \mathrm{~J} \mathrm{~cm}^{-2}$.

In a clinical PDT study, Biel $(31,32)$ described the treatment of 65 patients with neoplastic disease of the head and neck. Among these were seven patients with a T1 squamous cell carcinoma of the tongue or the floor of the mouth. Patients were treated $48 \mathrm{~h}$ after injection of Photofrin (2.0 mg kg-1) with $630 \mathrm{~nm}$ light at $50-75 \mathrm{~J} \mathrm{~cm}^{-2}$ and $150 \mathrm{~mW}$ $\mathrm{cm}^{-2}$. For tumours greater than $3 \mathrm{~mm}$ depth, cylindrical diffuser implants were used. No adverse reactions were described. The results of this study are very promising because PDT was found to be effective, especially in the treatment of T1 tumours and carcinoma in situ (CIS). However, much less impressive results were achieved in treating deeply-invasive carcinomas. The present authors fully agree with the conclusions of the study that adequate delivery of the laser light to the tumour bed plays an important role, and that it is difficult to compare or evaluate the effectiveness of PDT because of the lack of well-defined standards for PDT treatments with regard to drug dosage, light delivery systems and optical dosimetry.

\section{CONCLUSIONS}

Internal reflection and light scattering have a strong influence on the true-light fluence in tissue. Normal tissues do retain the photosensitizer and are susceptible to PDT. The amount of PDT-induced damage was found to be photosensitizer and light-dose dependent.

An additional aim of this study was to define a treatment window for PDT of chemically induced dysplastic lesions and squamous cell carcinoma of the rat palatal mucosa. In this study, combinations of photosensitizer $\geq 5 \mathrm{mg}$ $\mathrm{kg}^{-1}$ and light $\geq 100 \mathrm{~J} \mathrm{~cm}^{-2}$ resulted in distinct permanent damage. As damage to 
normal tissues should be at least reversible, these values define the upper limits of the treatment window. Furthermore, the use of light of $514.5 \mathrm{~nm}$ seems to be more appropriate for PDT of superficial mucosal lesions than $625 \mathrm{~nm}$ because it is capable of adequately exciting porphyrin without damaging structures at deeper levels. In humans, the dimensions in the oral cavity are much larger than in rats, so the effects of depth of penetration to surrounding anatomical structures, will be far less devastating than those described in this study. Nevertheless, this study shows that anatomical structures beyond the target volume are prone to permanent PDT damage. Phenomena, such as the occurrence of epithelial inclusion cysts, ankylosis of teeth, pulp necrosis and necrosis of bone, seriously complicate clinical application of PDT in the oral region. Additional in vivo PDT studies are, therefore, needed to further establish optimal treatment protocols and to define the true merit of PDT in the treatment of premalignant and malignant lesions of the oral mucosa.

\section{ACKNOWLEDGEMENTS}

This work was supported by the Dutch Cancer Society (grant GUKC 91-04). The authors wish to thank Ms C. A. A. M. Nooren and Mr O. C. Speelman for their assistance in this study, and $\mathrm{Mr} \mathrm{H}$. Vuik and $\mathrm{Mr} \mathrm{S}$. Sliwa for the photographs.

\section{REFERENCES}

1. Foote CS. Mechanisms of photooxygenation. Prog Clin Biol Res 1984, 170:3-18

2 Bugelski P, Porter C, Dougherty TJ. Autoradiographic distribution of haematoporphyrin derivative in normal and tumor tissue of the mouse. Cancer Res 1981, 41:4606-461

3 Bellnier DA, Ho YK, Pandey RK, Missert JR, Dougherty TJ. Distribution and elimination of Photofrin II in mice. Photochem Photobiol 1989, 50:221-8

4 Gomer CJ, Dougherty TJ. Determination of $\left[{ }^{3} \mathrm{H}\right]-$ and $\left[{ }^{14} \mathrm{C}\right]$ hematoporphyrin derivative distribution on malignant and normal tissue. Cancer Res 1979, 39:146-51

5 Kessel D. Proposed structure of the tumor-localizing fraction of HPD (hematoporphyrin derivative). Photochem Photobiol 1986, 44:193-6

6 Wilson BC, Firnau G, Jeeves WP, Brown KL, Burns-McCormick DM. Chromatographic analysis and tissue distribution of radiocopper labelled haematoporphyrin derivatives. Lasers Med Sci 1988, 3:71-80

7 Ernst H, Sassy T, Sroka R, Gossner L, Hahn EG, Ell C. Ultrastructural changes in normal rat colon induced by photodynamic therapy. Lasers Med Sci 1994, 9:17-25
8 Marijnissen JPA, Jansen H, Star WM. Treatment system for whole bladder wall photodynamic therapy with in vivo monitoring and control of light dose rate and dose. I Urol 1989, 142:1851-5

9 Muller PJ, Wilson BC. Photodynamic therapy of malignant primary brain tumors: clinical effects, postoperative ICP, and light penetration of the brain. Photochem Photobiol 1987, 46:929-35

10 Grossweiner LI. Light dosimetry model for photodynamic therapy treatment planning. Lasers Surg $M e d$ 1991, 11:165-73

11 Wenig BL, Kurtzman DM, Grossweiner LI, Mafee MF, Harris DM, Lobraico RV, Prycz RA, Appelbaum EL. Photodynamic therapy in the treatment of squamous cell carcinoma of the head and neck. Arch Otolaryngol Head Neck Surg 1990, 116:1267-70

12 Star WM, Versteeg AAC, Van Putten WL, Marijnissen JPA. Wavelength dependence of hematoporphyrin derivative photodynamic treatment effects on rat ears. Photochem Photobiol 1990, 52:547-54

13 Marijnissen JPA, Star WM. Quantitative light dosimetry in vitro and in vivo. Lasers Med Sci 1987, 2:235-41

14 Patterson MS, Wilson BC, Wyman DR. The propagation of optical radiation in tissue I. Models of radiation transport and their application. Lasers Med Sci 1991, 6:155-68

15 Patterson MS, Wilson BC, Wyman DR. The propagation of optical radiation in tissue II: optical properties of tissues and resulting fluence distribution. Lasers Med Sci 1991, 6:379-90

16 Van Gemert MJC, Berenbaum MC, Gijsbers GHM. Wavelength and light-dose dependence in tumour phototherapy with haematoporphyrin derivative. $B r J$ Cancer 1985, 52:43-9

17 Bellnier DA, Prout GRJ, Lin CW. Effects of $514.5 \mathrm{~mm}$ argon ion laser radiation on hematoporphyrin derivative treated bladder tumor cells in vitro and in vivo. J Natl Cancer Inst 1985, 74:617-26

18 Pope AJ, Masters JR, MacRobert AJ. The photodynamic effect of a pulsed dye laser on human bladder carcinoma cells in vitro. Urol Res 1990, 18:267-70

19 Witjes MJH, Speelman OC, Nikkels PGJ, Nooren CAAM, Nauta JM, van der Holt B, Van Leengoed HLLM, Star WM, Roodenburg JLN. In-vivo fluorescence kinetics and localization of aluminium phthalocyanine disulphonate in an autologous tumour model. Br J Cancer 1996, 73:573-80

20 Star WM, Marijnissen JPA. Calculating the response of isotropic light dosimetry probes as a function of the tissue refractive index. Appl Opt 1989, 12:2288-91

21 Marijnissen JPA, Star WM. Calibration of isotropic light dosimetry probes based on scattering bulbs in clear media. Phys Med Biol 1996, in press

22 Chaudhuri K, Goldblatt PJ, Kreimer-Birnbaum M, Keck RW, Selman SH. Histological study of the effect of hematoporphyrin derivative photodynamic therapy on the rat jejunum. Cancer Res 1986, 46:2950-3

$23 \mathrm{Pe}$ MB, Sano K, Inokuchi T. Effects of photodynamic therapy in the normal mouse tongue. J Oral Maxillofac Surg 1993, 51:1129-34

24 Biel MA, Janssen W, Trump MF. Photodynamic therapy to the oral cavity, tongue and larynx: a canine normal tissue tolerance study. Lasers Med Sci 1995, 10:13-8

25 Monnier P, Savary M, Fontolliet C, Wagnieres G, Chatelain A, Cornaz P, Depeursinge C, Van den Bergh 
H. Photodetection and photodynamic therapy of 'early' squamous cell carcinomas of the pharynx, oesophagus and thracheo-bronchial tree. Lasers Med Sci 1990, 5:149-69

26 Meyer M, Speight P, Bown SG. A study of the effects of photodynamic therapy on the normal tissues of the rabbit jaw. Br J Cancer 1991, 64:1093-7

27 Star WM, Marijnissen JPA, Jansen H, Keijzer M, Van Gemert MJC. Light dosimetry for photodynamic therapy by whole bladder wall irradiation. Photochem Photobiol 1987, 46:619-24

28 Marijnissen JPA, Star WM, in't Zandt HJA, D'Hallewin MA, Baert L. In situ light dosimetry during whole bladder wall photodynamic therapy. Phys Med Biol 1993, 38:567-82
29 Pass HI. Photodynamic therapy in oncology: mechanisms and clinical use. J Natl Cancer Inst 1993, 85:443-56

30 Spike RC, Payne AP, Thompson GG, Moore MR. Highperformance liquid chromatographic analyses of porphyrins in hamster Harderian glands. Biochim Biophys Acta 1990, 1034:1-3

31 Biel MA. Photodynamic therapy and the treatment of neoplastic disease of the larynx, oral cavity, pharynx and tracheobronchial tree. Proc SPIE 1993, 1881:10-9

32 Biel MA. Photodynamic therapy of head and neck cancers. Semin Surg Oncol 1995, 11:355-9

Key words: Photodynamic therapy; Photofrin; Oral mucosa; Normal tissue damage; Light dosimetry 